\title{
Severe acute respiratory syndrome coronavirus 2 targeted antibodies cocktail and $B$ cell receptor interplay: interventions to trigger vaccine development
}

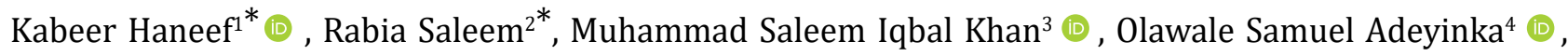 \\ Sadeeq Banday ${ }^{5}$, Muhammad Umer Asghar ${ }^{6,7}$, Zia Ur Rahman $\left.{ }^{4}{ }^{(}\right)$, Zainab Fatima ${ }^{8}$ \\ ${ }^{1}$ School of Life Science, Institute for Immunology, Tsinghua University, Beijing 100084, China \\ ${ }^{2}$ Department of Pediatric Haematology, Oncology and BMT, The Children's Hospital and Institute of Child Health, Lahore \\ 53700, Pakistan \\ ${ }^{3}$ Department of Biochemistry, Cancer Institute of the second affiliated hospital, School of Medicine, Zhejiang University, \\ Hangzhou 310058, Zhejiang, China \\ ${ }^{4}$ Centre of Excellence in Molecular Biology, University of the Punjab, Lahore 53700, Pakistan \\ ${ }^{5}$ School of Agriculture Sciences and Food Technology, Shandong University of Technology, Zibo 255000, Shandong, China \\ ${ }^{6}$ National Institute for Biotechnology and Genetic engineering (NIBGE), Faisalabad 38000, Pakistan \\ ${ }^{7}$ Pakistan Institute of Engineering and Applied Sciences (PIEAS), Nilore, Islamabad 45650, Pakistan \\ ${ }^{8}$ Department of Psychology, University of Gujrat, Punjab 50991, Pakistan
}

*Correspondence: Kabeer Haneef, School of Life Science, Institute for Immunology, Tsinghua University, Beijing 100084, China. Kabeerhaneef16@gmail.com; Rabia Saleem, Department of Pediatric Haematology, Oncology and BMT, The Children's Hospital and Institute of Child Health, Lahore 53700, Pakistan. Rabirehman51@gmail.com

Academic Editor: Wangxue Chen, National Research Council Canada, Canada

Received: April 29, 2021 Accepted: July 11, 2021 Published: August 31, 2021

Cite this article: Haneef K, Saleem R, Iqbal Khan MS, Adeyinka OS, Banday S, Asghar MU, et al. Severe acute respiratory syndrome coronavirus 2 targeted antibodies cocktail and B cell receptor interplay: interventions to trigger vaccine development. Explor Immunol. 2021;1:140-54. https://doi.org/10.37349/ei.2021.00011

\begin{abstract}
Coronavirus disease-2019 (COVID-19) caused by severe acute respiratory syndrome coronavirus (SARSCoV)-2 spread globally and creates an alarming situation. Following the SARS-CoV-2 paradigm, therapeutic efficacy is achieved via repurposing several antiviral, antibacterial, and antimalarial drugs. Innate and adaptive immune cells work close to combat infection through the intricate production of antibodies (Abs) and inflammatory cytokines. As an essential component of the immune system, Abs play an important role in eliminating viruses and maintaining homeostasis. B lymphocytes (B cells) are effector cells, stringent to produce neutralizing Abs to combat infection. After recognizing SARS-CoV-2 antigens by a surface receptor called B cell receptors (BCRs) on the plasma membrane, the BCRs transmembrane signal transduction and immune activation results in $\mathrm{Ab}$ production and development of immune memory. Thus, it ensures that plasma B cells can quickly start an intricate immune response to generate efficient protective Abs to clear the pathogen. Nevertheless, considering therapeutic challenges in the context of the new coronavirus pandemic, this review addresses the molecular mechanism of the immune activation and function of novel SARSCoV-2 specific B cells in the production of SARS-CoV-2 specific Abs. Additionally, these studies highlighted


the Ab-mediated pathogenesis, the intriguing role of nano-scale signaling subunits, non-structural proteins during COVID-19 infection, and structural insights of SARS-CoV-2 specific Abs.

\section{Keywords}

Severe acute respiratory syndrome coronavirus 2, humoral immunity, B cell receptor, vaccine production, adaptive immunity, antibody pathogenesis, cytokine responses, non-structural protein

\section{Introduction}

Undoubtedly, the whole world lives with the reality of coronavirus disease-2019 (COVID-19) disease, a pandemic that has claimed thousands of lives. The novel coronavirus disease (nCOVID-19) caused by severe acute respiratory syndrome coronavirus (SARS-CoV)-2 has been reported from Wuhan with remarkable consequences and has spread worldwide, creating alarming situations [1-3]. Phylogenetic analysis of SARSCoV- 2 reveals proximity with $\beta$ subgroup [4], placed in Coronaviridae family [5]. Interestingly, SARS-CoV-2 shows a higher tendency to bind human angiotensin-converting enzyme-2 (hACE2) in contrast to severe acute respiratory syndrome coronavirus (SARS-CoV) and the Middle East respiratory syndrome (MERS) to induce lungs infection [6]. Genetic annotations revealed that the SARS-CoV-2 genome potentially encodes four structural [membrane (M), nucleocapsid $(\mathrm{N})$, spike (S), envelope (E)] and six accessory proteins $(7,8,7 a, 7 b, 3 a, 6)$ [1]. Receptor-binding domain (RBD), a subunit of surface $S$ glycoprotein, triggers attachment with host hACE2 [7]. Intriguing genome mapping reveals $79.6 \%$ identity features between SARS-CoV-2 and SARS-CoV [8]. Following the tremendous increase in death toll and severity of the disease, healthcare emergencies have posed an urgent call for developing vaccines, suitable drug candidates, and high-affinity antibodies (Abs) to combat the SARS-CoV-2 pandemic [5, 9-12]. At present, several antiviral drugs (remdesivir, umifenovir, lponavir, ritonavir) alone or in combination with antimalarial (chloroquine) and antibacterial are repurposed to achieve therapeutic efficacy [1,13-15]. Additionally, convalescent plasma (CP) therapy is beneficial in the treatment of SARS-CoV-2 infected patients $[11,12,15]$. However, severe threats and devastation in lung pathologies are caused by SARS-CoV-2 in contrast to SARS-CoV and MERS coronavirus (MERS-CoV) [16, 17].

Following infection, innate (macrophage, dendritic cells) and adaptive (B and T) immune cells coordinate efficiently to neutralize the pathogens $[18,19]$. In vivo studies have revealed that following interaction of external invading Ags with a surface-anchored receptor called the B cell receptor (BCR), a series of signal transduction events occurs via phosphorylation of the immunoreceptors tyrosine-based activation motif (ITAM) interlinked immunoglobulin $(\operatorname{Ig}) \alpha, \operatorname{Ig} \beta$ domains via underlying kinase phosphorylated spleen tyrosine kinase (pSyk) [2]. These events led to the subsequent recruitment of proximal signaling molecules and adaptor proteins to produce neutralizing Abs (NAbs) and develop immune memory [20, 21]. B cell receptors (BCRs) configuration reveals noncovalent meticulous interactions of membrane-tethered with Ig $\alpha$, $\operatorname{Ig} \beta$ [21-23]. Interestingly BCRs transduced proximal signaling further develop immune memory to combat reoccurrence of infection [24]. Several studies have reported that $B$ lymphocytes (B cells) producing effective SARS-CoV-2 specific NAbs (IgG, IgM, IgE) have been successfully isolated and identified in convalescent patient's plasma [25]. Multiple technical platforms, including immunology, high-speed, high-resolution livecell single-molecule fluorescence imaging technologies, have illustrated potential mechanisms to uncover a series of events showing how B cells undergo Ab production [26]. Here we review the literature, highlighting how nanoscale signaling immune (B and T) cells contribute to COVID-19 mediated infection. Furthermore, we illustrate some Ab-mediated parameters against SARS-CoV-2 concerning some cross-sectional studies. These studies could provide detailed insights in the future for the development of therapeutic entanglements for SARS-CoV-2 infection (Figure 1). 


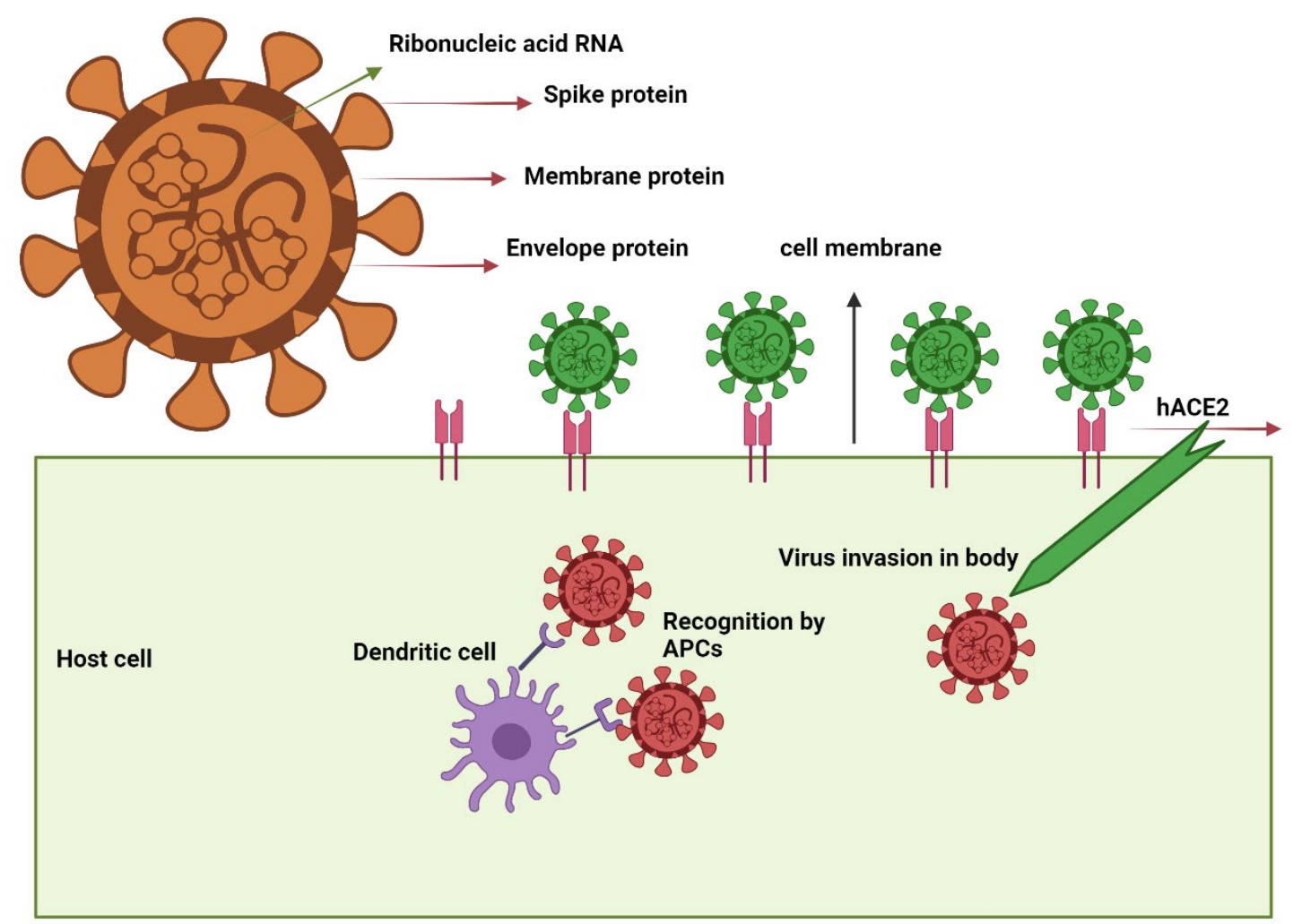

Figure 1. SARS-CoV-2 virus schematic illustration showing the target proteins and mechanism of entry into the host cell. SARS$\mathrm{CoV}-2$ virus structural proteins include $\mathrm{S}, \mathrm{M}$, and $\mathrm{E}$ protein. When SARS-CoV-2 enters host cells, it is recognized by the hACE2 and processed by APCs, particularly dendritic cells, which initiate the signaling cascade events

\section{Adaptive immunity against SARS-CoV-2, collective contributions of intricate nano-scale signaling subunits and $T$ cell subsets during infection}

Antiviral immunity emerged through the intricate association between the Ag and APCs through delicate interactions confronted through external projections and dendrites of in vivo APCs [5]. Following viral infection, bridge cells (macrophages and dendritic cells) are infiltrated at the infection tropism to combat infection [27]. Major histocompatibility complex class (MHC)I molecules are required for the efficient processing and presentation of exogenous invading Ags to B cells [5], which results in humoral immune responses and activation of $\mathrm{CD}^{+} \mathrm{T}$ cells [5]. However, sophisticated mechanisms achieved through collective contributions of interferons (IFNs) and interleukins (IL), including IFNs, IL-2, IL-12, and IL-33, constrain viral replication and further assassinate virus-infected cells [28, 29]. Besides, $\mathrm{T}$ cell interventions contribute a significant role to clear infection through the production of inflammatory cytokines, thus offering a comprehensive strategy to prevent the reoccurrence of COVID-19 disease [29]. Similar studies have shown how $\mathrm{T}$ cell subset counts fluctuate during COVID infection [30]. Typically, $\mathrm{T}$ cell counts in COVID-19 patients with severe and moderate symptoms seem diminished $(541.5 / \mu \mathrm{L})$ than the normal range (955.0-2,860.0/ $\mu \mathrm{L})[31]$, in contrast to B cell and NKT cells [32, 33].

Similarly, the key difference in $\mathrm{CD} 4^{+}$and $\mathrm{CD} 8^{+} \mathrm{T}$ cells reveal the onset of differential cytokine expressions during SARS-CoV-2 infection [30]. T cell subset contributions during SARS-CoV-2 infection have already been investigated, offering new insights to designing a vaccine against SARS-CoV-2. Similar interventions have demonstrated the influence of $\mathrm{T}$ cell subsets such as $\mathrm{T}$ helper (TH)1, TH2, TH17, and regulatory $\mathrm{T}$ cell (Treg) on IL and cytokine secretion mechanisms during SARS-CoV-2 infection, with TH1 cells secreting significantly less IL-6 [31, 34]. Interestingly, TH2 cells during COVID-19 infection triggered IL-4 and IL-3 cytokine production [35]. Corresponding studies reported that $\mathrm{T}$ cells, especially naïve regulatory and induced Treg cells (iTreg) $\left[\mathrm{CD} 45^{\mathrm{RO}+} \mathrm{CD} 3^{+} \mathrm{CD} 4{ }^{+} \mathrm{CD} 25^{+} \mathrm{CD} 127^{\text {low }}\right.$, iTreg], seem diminished in severe COVID-19 infected patients, thereby exaggerating the immune response to trigger disease severity [36]. Besides the activation of costimulatory receptors like-CD28, OX40 (CD134), and 4-1BB (CD137) were observed during 
activation of $\mathrm{CD}^{+} \mathrm{T}$ cells [37]. Co-stimulatory receptor molecules increase in patients with SARS-CoV-2 infection [37]. A considerable increase in OX40 and 4-1BB expression was identified in COVID-19 infected individuals compared to healthy controls [38]. Inflammatory cytokines [tumor necrosis factor (TNF)- $\alpha$, IL-8, 1L-2, IL-10] are mostly co-related to disease.

Several cellular activities, such as cellular exhaustion, have been investigated during the chronic phase of COVID-19 infection, affecting disease progression [39]. Infected cells mainly express programmed cell death protein 1 (PD-1), cytotoxic T-lymphocyte-associated Ag 4 (CTLA-4), T cell Ig and mucin domain 3 (Tim-3) Ags fluctuating COVID-19 infection [40]. To better decipher the lungs pathology during SARS-CoV-2 infection, several interventions revealed the collective contributions of C-X-C motif (CXC) family receptors, including CXC ligand (CXCL) 10 (CXCL-10), C-C chemokine ligand (CCL)2, CCL5 stringent to trigger the site-specific aggregation and recruitment of neutrophils in lungs. Potentially, these mechanisms trigger lung injury due to the release of antimicrobial factors such as reactive oxygen species (ROS), proteases, and neutrophil extracellular traps (NETs) [41]. Other studies have revealed the expression of CXCL8 (IL-8), a major neutrophil-attracting chemokine in patients with severe COVID-19 infection [42]. Cytotoxic T lymphocytes induce apoptosis by various means such as the production of cytotoxic granules (perforin and granzyme), expression of cytokines, such as TNF, Fas ligand (FasL), and TNF-related apoptosis-inducing ligand (TRAIL) in virus-infected cells [43].

A large proportion of biomarkers have been identified from humans. To investigate mRNA and DNA, PCR-directed amplification techniques and protein assays are broadly undergoing [44]. Similarly, Ab production against specific SARS-CoV-2 viral infections, including NAbs against N, RBD, and S proteins, could be detected to confirm the persistence of the virus [10]. Patients suffering from SARS-CoV-2 infection have been reported positive for Ab production [10]. Several studies have reported the onset of triggered cytokine (IL-18, IL-8, IL-6) production in SARS-CoV-2 infected patients, suggesting positive biomarkers to trigger diagnostic levels [45]. Similar investigations have reported diminished levels, especially IL-1, IL-4, IL-12, and TNF-a during the SARS-CoV-2 diseased [46].

\section{B cell receptor signaling and the generation of protective Abs during SARS- CoV-2 infection}

Following the interaction of Ags, BCR undergoes signal transduction events through phosphorylation of ITAMs to produce plasma cells to generate effective Abs [22]. BCRs delicate configuration possessed membrane-tethered Ig, non-covalently associated with Iga, Ig $\beta$ domains (Figure 2) [20]. Following BCR interactions with SARS-CoV-2 structural Ags, BCRs undergo series of signal transduction events [20]. These events lead to several well-ordered molecular events, including isotype class switching, affinity maturation, and $\mathrm{Ab}$ production against SARS-CoV-2 $[5,20,21]$. BCR's intricate, methodical configuration reveals efficient capability to translate the external physical, chemical, and antigenic cues and harbor sophisticated mechanisms of generating chemical signal entities to reshape the immune mechanism [22, 26]. However, potential investigations on how BCRs of SARS-CoV-2 specific B cells isolated from CP of infected people respond to $B C R$ signaling, spatiotemporal dynamics, and $A b$ production remains obscure.

Potential contributions of B cells response during SARS-CoV-2 pandemic are crucial during vaccine production. Similar interventions reported that Igs (IgG, IgM) concentrations were disturbed after SARS-CoV-2 infection [47]. Similar studies indicated that SARS-CoV-2 exposed patients showed positivity for SARS-CoV-2 specific IgG and IgA at some time frames [47-50]. Patients experiencing the active phase of SARS-CoV-2 infection generally showed peak amounts of Abs in contrast to patients $[31,48,51]$, with relative IgG (amounts of 6.3 compared to 2.1) in a time of 30-45 days after the first symptoms surfaced [2]. Similar speculations have reported that patients suffering from active, mild, or severe SARS-CoV-2 infection develop Abs despite disturbances in B cell counts and IgA, IgM, and IgG expression profiles [3].

As an adaptive immune system, it's vital to elaborate on B cell counts and their role during the SARSCoV-2 infection trajectory [52, 53]. Several studies have reported that following SARS-CoV-2 infection, the magnitude of Ab-secreting B cells was significantly higher than in healthy individuals, implying that they 
could serve as a prognostic indicator of disease [4]. Furthermore, these studies highlighted a reduced number of marginal zone B (MZB) cells in SARS-CoV-2 infected people compared to healthy individuals [54]. Similar studies have demonstrated that the triggered population of Ab-secreting plasma cells in patients correlates with disease severity; however, determining whether the Abs secreted are protective or pro-inflammatory requires additional attention [55]. B cell types, especially MZB and follicular B (FBC) cells were reported altered in SARS-CoV-2 infection, suggesting efficient interplay of $B$ cells between innate and adaptive immune cells [56]. In comparison between SARS-CoV-2 infected and healthy people, naïve B cell count frequencies were found similar, irrespective of the diseased condition [57]. SARS-CoV-2 patients exhibit a reduction of CXC receptor (CXCR) 5 expression in major B cell subsets, suggesting a hallmark of disease [58, 59]. However, the changes in the B cell subsets were not associated with co-infection, immune suppression, or treatment with steroids or other clinical features (Figure 2).

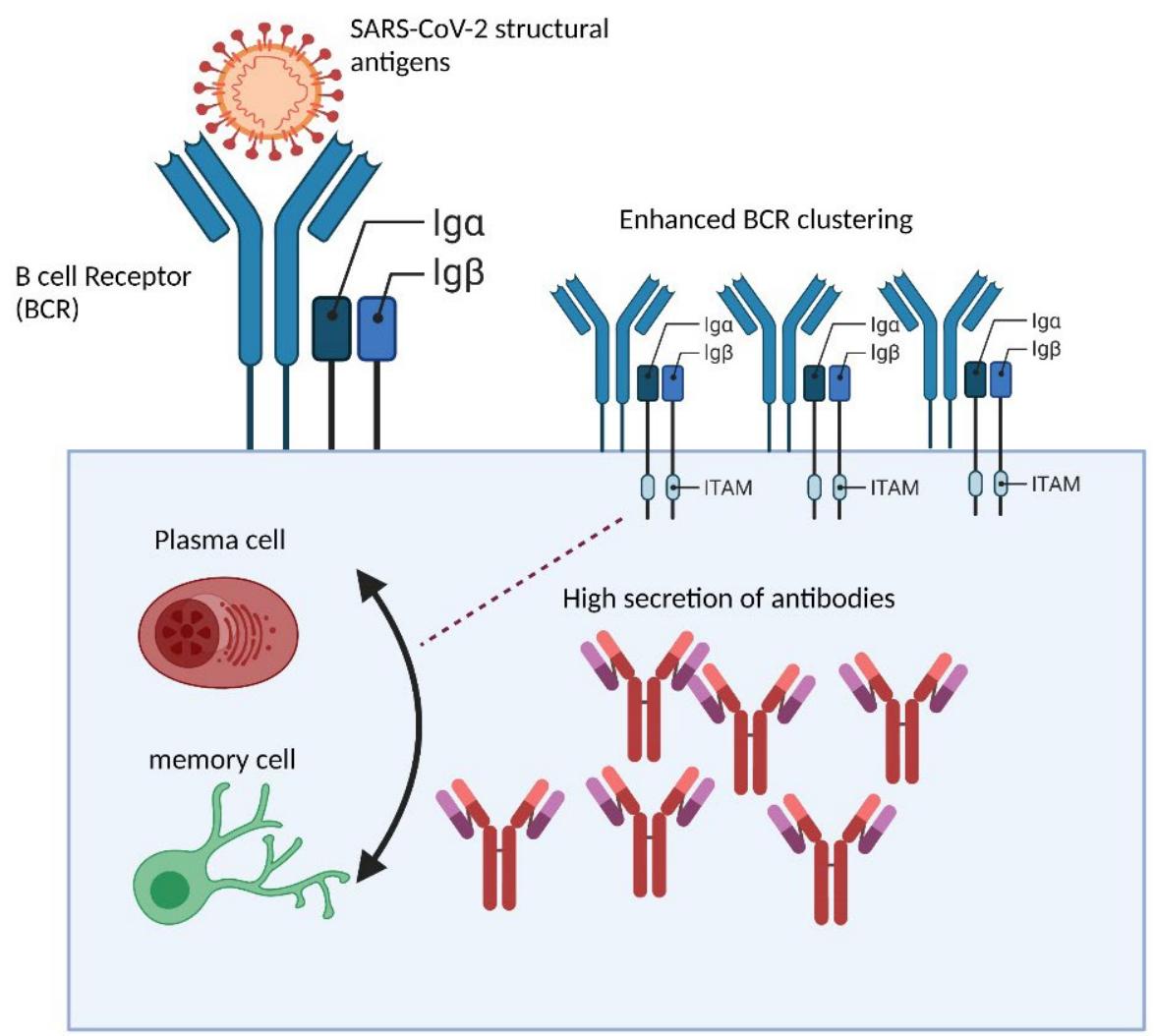

Figure 2. BCRs surface interaction with SARS-CoV-2 structural glycoprotein antigens triggers humoral immune response. Surface interaction of SARS-CoV-2 structural antigens with BCR initiates the aggregation of BCRs into BCR microclusters, through the phosphorylation of ITAMs interlinked Iga, Ig $\beta$ domains which are subsequently carried through underlying enzymes resulting in triggered series of humoral immune responses to combat infection

\section{SARS-CoV-2 mediated immunopathogenesis through polyprotein and Ag involvement}

Concerning COVID-19 pathogenesis, several other significant factors play a contributing role [5]. However, considering the immune system during SARS-CoV-2 infection, an intricate decisive step in the process of SARS-CoV-2 induced pathogenesis is cellular receptor recognition [59]. S protein having RBD and S2 on viral envelop, recognize angiotensin-converting enzyme (ACE)2 ligand on bronchioles epithelial cells [60]. This recognition process is arbitrated by transmembrane serine protease 2 (TMPRSS2) [61], disintegrin metalloproteinase 17 (ADAM17) [62], membrane proteins (vimentin and clathrin), and angiotensin II type 1 a receptor (AT1a R). All these facilitate the coalition of the virus envelope following the viral RNA entrance into the cytoplasm of the target cells [63]. Upon viral entry into the host cell, this mechanism induces autophagy and eventually hypoxia which may lead to SARS-CoV-2 induced pneumonia acute respiratory distress syndrome (ARDS), and even death [64]. Additionally, COVID-19 could target and infect various cells having ACE2 ${ }^{+}$receptors [65]. Many studies isolate the SARS-CoV-2 from the $67 \%$ of patients who develop diarrhea during the infection, indicating that the disease may spread to other organs (heart, kidney, and 
small intestine) with high ACE2 expression [66]. However, ACE2+ receptors on other cells like intestine enterocytes directly correlated with age [58], indicating that children have less susceptibility to infection than old-age persons [67].

A recent study confirms that SARS-CoV-2 can use host cell novel receptor CD147 to gain entry into the host cells besides ACE2 $[68,69]$. People having asthmatic and diabetic complications lead to the escalation of CD147 expression levels [70]. SARS-CoV-19 virus RNA behaves as a toxin due to Ag consequences with toll-like receptor (TLR)7 [71], via myeloid differentiation factor 88 (MyD88)-dependent and TIR-domain-containing adapter-inducing interferon-beta (TRIF) dependent pathways [72]. Pro-inflammatory cytokines (IL-1, IL-6, TNF- $\alpha$ ) and type I IFN- $\alpha / \beta$ expression can trigger the cytokine storm phenomena caused by vascular leakage and severe SARS-CoV-2 infection [73, 74]. Corresponding studies showed that genetic inactivation of the TLR4 gene might reduce lung injury in SARS-CoV-2 infected patients [75]. Many studies revealed that TLR4 activation induces the most substantial immune effect in cytokine release [75]. However, SARS-CoV-2 is unlikely to activate TLR4 directly, as TLR4 responds to bacteria and viruses like the dengue virus [nonstructural protein (NSP) 1].

\section{Role of NSP during COVID-19 infection and possible targets for vaccine development}

To deeply investigate the mechanism of SARS-CoV-2 mediated pathogenesis, NSPs appear necessary for RNA transcription, translation, and viral replication in SARS-CoV-2 infection [76]. The structural dogma of SARS-CoV-2 reveals the intricate involvement of NSPs to ameliorate lung pathology. Mechanistically, NSPs proteins trigger lung pathology through triggered replication and evasive immune mechanisms [76]. SARS-CoV-2 genome is supplemented with NSP3 and NSP5 regions having proteolysis activity [papainlike protease (PLpro), 3C-like protease (3CLpro)] which helps the cleavage of polyproteins into NSPs 1-16 [5]. NSPs are encoded through Orf1a/Orf1 $a b$ particles [76]. The viral attachment and host response are dependent on the numbers of NSPs (NSP3, NSP5, NSP8, NSP9, NSP10) [76]. NSP3, having 1945 amino acids, is the prime NSPs in the SARS-CoV-2 genome and subsumes many functional domains like MHC-I and MHC-II $T$ cell and B cell activation [61]. Besides, that could be a safe target for vaccine development [77]. NSP3 and NSP9- SARS-CoV-2 exhibit a high sequence similarity and a higher degree of functional conservation with SARS-CoV interlinked NSP3 and NSP9 regions [78]. NSP9 plays a significant role in the SARS-CoV-2 infection trajectory [79]. The NSP9 intervenes in viral replication, virulence, and viral genomic RNA multiplication [79]. The NSPs proteins can target therapeutic agents due to their precise biological function and vibrant enzyme active sites. The cocktail vaccine containing a structural protein (SP) and an NSP would stimulate effective complementary immune responses [80,81].

\section{Structural interventions of SARS-CoV-2 specific Abs and humoral immune responses}

Anti-SARS-CoV-2 specific Abs and fraction analysis of Abs seroconversion (IgM, IgG, IgE) were investigated among infected patients, suggesting different disease severity outcomes [44]. Structural features of SARSCoV-2 specific Abs and detailed insights for binding with high-affinity functional epitopes are fundamental to achieving better therapeutic efficacy [10]. Potential illustrations regarding the characterization of structural and neutralizing parameters of SARS-CoV-2 specific Abs have provided detailed insights to better decipher the mechanism of Ab-mediated pathogenies during different stages of development [82]. Healthy individuals reveal the persistence of fucosylated IgG [83], while non-fucosylation has been observed during pregnancy, increasing the risk of disease severity [84]. Considering structural parameters of Abs, several experimental inculcations have developed anti-SARS-CoV-2 Abs, harboring the stringent potential to devastate infected cells through Ab-dependent cellular cytotoxicity (ADCC) mechanism [85]. Persistence of fucosylated Abs in serum of severely ill patients target glycoprotein (S) of SARS-COV-2 in contrast to mild and asymptomatic patients, suggesting efficient potential to neutralize the infection [10].

Overall, magnitude, efficacy, and quantity consideration of $\mathrm{Ab}$ responses are fundamental to achieve better therapeutic efficacy [86]. The potential capability of binding with specific epitopes triggers the neutralization response [10]. For example, the crystallizable fragment $(\mathrm{Fc})$ mediated region in the case of 
influenza virus is required to achieve neutralization [87, 88], while in terms of SARS-CoV, NAbs blocked hACE2 [6, 89]. Following SARS-CoV-2 infection, collaborative immune mechanism amplified through Abs, complement proteins, bridge APCs (macrophages, dendritic cells) trigger immune cascade activation resulting in clearance of pathogens [56, 90]. Interestingly Ab-dependent enhancement (ADE) phenomenon emerged during specific frames of anti-pathogen-associated molecular patterns (PAMPs), lead to the devastation of the immune response $[10,91]$. However, in-depth investigations illustrating how the ADE phenomenon could provide deep insights to target specific molecules to prevent autoimmune pathologies is still matter of considerations. The persistence of Fc receptors (FcRs) on immune cells (monocytes and macrophages) triggers immunopathology during dengue virus infection [92]. In terms of SARS-CoV and ACE2, endosomal $\mathrm{pH}$ and protease independent pre-existing FcRs interactions facilitate virus entry mechanism [93].

Pre-existing investigations have identified several factors (concentration, specificity, affinity, and isotype switching) stringent to check interplay, whether anti-SARS-CoV-2 Abs are neutralizing, host protective, damaging, and cause ADE or inflammation [10,94]. Similar speculations have revealed that mice immunized with SARS-CoV-2 vaccines encoding S and N portions produced (anti-N, S) NAbs with the same magnitude. At the same time, re-exposure triggered the onset of anti-SARS-CoV acquired $\mathrm{N}$, proteins Ab response with elevated expression of cytokine and site-specific aggregation of neutrophils leading to the devastation of lungs pathology [95]. The low volume of Ab production in FcRs expression triggers ADE-mediated pathology [48]. Higher Ab concentrations direct anti-SARS-CoV-2 mediated targeting, suggesting Ab magnitude as a potential candidate to trigger ADE-mediated pathologies [48].

\section{Dynamic features of SARS-CoV-2 specific Abs during the infection}

Deciphering the dynamics parameters and optimizing NAbs production sequelae of SARS-CoV-2 infection is fundamental for efficient formulations of intricate strategies for developing therapeutic options and vaccines against SARS-CoV-2 coronavirus [96]. Several corresponding investigations have showed that virus magnitude seems triggered during the first week, followed by a gradual temporal decrease during the second week [4]. Enhanced infection load might be crucial to transmit the virus during disease severity [97-99]. Several investigations have reported the significant correlation of SARS-CoV-2 specif Abs with age and sex, exhibiting an increased Abs titers during severe infection in contrast to mild and asymptomatic infections [48, 49]. Additionally, corresponding speculations have reported the persistence of IgG and IgM after ten days of SARS-CoV-2 disease and the onset of seroconversion $[100,101]$. Studies conducted by Chen et al. [65] reported the augmented persistence of the hACE2 receptor in older patients in contrast to young people, posing severe threats of carrying an infection.

\section{The neutralizing potential of Abs against SARS-CoV-2, SARS-CoV, and MERS}

NAbs milieu induced through passive/active immunization or virus infection is crucial to combat disease $[9,56,102]$. Currently, several monoclonal NAbs, including Ag-binding fragments (Fab), variable region, and single-chain variable fragment ( $\mathrm{scFv}$ ) purified through cutting multidisciplinary approaches against MERS and SARS-CoV-2, are undergoing to treat COVID-19 infection [9]. The specified monoclonal region reveals specificity to bind respective SARS-CoV-2 S and RBD regions to further inhibit S2 mediated entry and attachment mechanisms, thus likely efficient to treat infections [103-105]. NAbs show cross-reactivity against SARS-CoV and MERS as summarized in Table 1. S230.15 and m386 NAbs targeting SARS-CoV showed a cross-neutralizing potential against SARS-CoV-2, interacting RBD surface proteins, and inhibiting binding potential with hACE2. Likewise, the humanized 80R NAbs have revealed the functional capability to disrupt the RBD-hACE2 mechanism [106-107]. However, its anti-SARS-CoV-2 potential is obscure yet. Experimental investigations using HEK293T cells to analyze the antiviral efficacy of mouse-derived NAbs against SARS-CoV viruses highlight the powerful role of blocking RBD-hACE2 interactions $[92,108]$. Currently, polyclonal Abs from CP of infected patients are considered comprehensive therapeutic modalities for treating patients suffering from SARS-CoV-2 infection [10-12]. Despite the emergence of NAbs, there is a desperate need for technologies to develop functional monoclonal Abs and determinants to treat SARS-CoV-2 patients directly [94]. 
Considering phylogenetic and genome homology features of SARS-CoV-2 with SARS-CoV and MERS, researchers are trying to figure out the cross-neutralizing potential of SARS-CoV Abs against SARS-CoV-2 [109-111]. The CR3022, humanized monoclonal Ab harbor neutralization efficacy against SARS-CoV, has been evaluated to show cross-neutralization against SARS-CoV-2, with stringent potential to inhibit RBD-hAEC2 binding interactions [50, 112] (Table 1). S1 specific serum NAbs from recovered animals and humans have shown cross-neutralizing potential against SARS-CoV [91], showing the intricate capability to mediate S protein-specific entry mechanisms. Moreover, it's imperative to apply SARS-CoV specific NAbs against the current SARS-CoV-2 infection wave after robust efficacy and trial studies [113]. In the future, these cross-reactive applications could help to design specific monoclonal Abs (MoAbs) with potential efficacy to bind SARS-CoV-2 specific PAMPs regions (Table 1) [10].

Table 1. Overview of Abs undergoing to treat SARS-CoV-2

\begin{tabular}{llllllll}
\hline Ab & $\begin{array}{l}\text { Isolating } \\
\text { tropism }\end{array}$ & $\begin{array}{l}\text { Potential } \\
\text { efficacy }(\boldsymbol{\mu g} / \mathbf{m L})\end{array}$ & $\begin{array}{l}\text { Binding affinity } \\
(\mathbf{n m o l} / \mathbf{L}, \mathbf{K d})\end{array}$ & $\begin{array}{l}\text { Potential } \\
\text { binding domain }\end{array}$ & $\begin{array}{l}\text { In vivo } \\
\text { activity }\end{array}$ & $\begin{array}{l}\text { Cross-reactivity } \\
\text { against SARS-CoV }\end{array}$ & References \\
\hline CR3022 & Humanized & 0.114 & $6.3-115$ & RBD & N/A & Present & {$[4]$} \\
CV-30 & Humanized & 0.003 & 3.6 & RBD & N/A & absent & {$[114,115]$} \\
COVA1-12 & Humanized & 1.4 & 2.7 & RBD & N/A & absent & {$[10,116]$} \\
CB6 & Humanized & 0.026 & 2.49 & RBD & N/A & absent & {$[117]$} \\
CCL12.1 & Humanized & 0.0222 & 5.83 & RBD & N/A & absent & {$[10]$} \\
4A8 & Humanized & 0.61 & 91.7 & RBD & NTD & absent & {$[9,103]$} \\
\hline
\end{tabular}

List of Abs undergoing to treat SARS-CoV-2, revealing potential isolating source tropism, binding specificity, affinity, and crossreactivity against SARS-CoV strain

\section{Conclusion}

We summarized, the intricate subunits' during SARS-CoV-2 infection and the potential possible parameters of Abs undergoing treating COVID-19 patients. Furthermore, we illustrate a brief overview of adaptive immune cell (B and T) interventions and immunopathology during COVID-19. There are so many Abs mediated parameters against SARS-CoV-2, but we can not list them all. Thus, anti-SARS-CoV-2 parameters should be paid explicit attention in the future to identify the epitope targets for the developments of monoclonal NAbs against SARS-CoV-2. Likewise, it is significant to investigate the role of BCR signaling and meticulous interventions of BCR interlinked signaling subunit response during BCR signaling in results to SARS-CoV-2 Ags. These studies could provide detailed insights for developing therapeutic entanglements against a cohort of pathogens and viral diseases.

\section{Abbreviations}

Abs: antibodies

ACE: angiotensin-converting enzyme

ADE: antibody-dependent enhancement

Ag: antigen

APCs: antigen-presenting cells

B cells: B lymphocytes

BCRs: B cell receptors

CCL: C-C chemokine ligand

COVID-19: coronavirus disease-2019

CP: convalescent plasma

CXCL: C-X-C motif ligand

FcRs: crystallizable fragment receptors

hACE2: human angiotensin-converting enzyme-2 
Ig: immunoglobulin

IL: interleukins

ITAM: immunoreceptor tyrosine-based activation motif

MERS: Middle East respiratory syndrome

MHC: major histocompatibility complex class

$\mathrm{N}$ : nucleocapsid

NAbs: neutralizing antibodies

NSP: non-structural protein

RBD: receptor-binding domain

S: spike

SARS-CoV: severe acute respiratory syndrome coronavirus

TH: T helper

TLR: toll-like receptor

TNF: tumor necrosis factor

\section{Declarations}

Acknowledgments

The author is thankful to Tsinghua University, School of Life Science (SLS) for providing all kind of facilities to prepare the manuscript.

\section{Author contributions}

$\mathrm{KH}$ and RS are the main authors of this manuscript who designed the manuscript and content outlines; MUA, MSIK, and ZUR provide technical assistance and revise the manuscript critically; ZF and OSA provide critical overview and support in figure drafting. SB carefully overviewed and revised the manuscript.

\section{Conflicts of interest}

The authors declare that they have no conflicts of interest.

\section{Ethical approval}

Not applicable.

\section{Consent to participate}

Not applicable.

\section{Consent to publication}

Not applicable.

Availability of data and materials

Not applicable.

\section{Funding}

Not applicable.

\section{Copyright}

(C) The Author(s) 2021. 


\section{References}

1. Galluccio F, Ergonenc T, Garcia Martos A, Allam AE, Pérez-Herrero M, Aguilar R, et al. Treatment algorithm for COVID-19: a multidisciplinary point of view. Clin Rheumatol. 2020;39:2077-84.

2. Yang Y, Peng F, Wang R, Yange M, Guan K, Jiang T, et al. The deadly coronaviruses: the 2003 SARS pandemic and the 2020 novel coronavirus epidemic in China. J Autoimmun. 2020;109:102434.

3. Sun J, He WT, Wang L, Lai A, Ji X, Zhai X, et al. COVID-19: epidemiology, evolution, and cross-disciplinary perspectives. Trends Mol Med. 2020;26:483-95.

4. Guo YR, Cao QD, Hong ZS, Tan YY, Chen SD, Jin HJ, et al. The origin, transmission and clinical therapies on coronavirus disease 2019 (COVID-19) outbreak - an update on the status. Mil Med Res. 2020;7:11.

5. Haneef K, Asghar MU, Ali A. Novel immunogenomic insights of corona virus disease (COVID-19): available potential immunotherapeutics, current challenges, immune cell recognition and ongoing managerial strategies. Biomed Res Ther. 2020;7:3906-15.

6. Chen X, Li R, Pan Z, Qian C, Yang Y, You R, et al. Human monoclonal antibodies block the binding of SARSCoV-2 spike protein to angiotensin converting enzyme 2 receptor. Cell Mol Immunol. 2020;17:647-9.

7. Chen WH, Hotez PJ, Bottazzi ME. Potential for developing a SARS-CoV receptor-binding domain (RBD) recombinant protein as a heterologous human vaccine against coronavirus infectious disease (COVID)-19. Hum Vaccin Immunother. 2020;16:1239-42.

8. Xie M, Chen Q. Insight into 2019 novel coronavirus-an updated interim review and lessons from SARSCoV and MERS-CoV. Int J Infect Dis. 2020;94:119-24.

9. Ho M. Perspectives on the development of neutralizing antibodies against SARS-CoV-2. Antib Ther. 2020;3:109-14.

10. Lu L, Zhang H, Zhan M, Jiang J, Yin H, Dauphars DJ, et al. Antibody response and therapy in COVID-19 patients: significance in vaccine development. bioRxiv 2020080166 [Preprint]. 2020 [cited 2020 Aug 6]. Available from: https://www.preprints.org/manuscript/202008.0166/v1

11. Chen L, Xiong J, Bao L, Shi Y. Convalescent plasma as a potential therapy for COVID-19. Lancet Infect Dis. 2020;20:398-400.

12. Duan K, Liu B, Li C, Zhang H, Yu T, Qu J, et al. Effectiveness of convalescent plasma therapy in severe COVID-19 patients. Proc Natl Acad Sci U S A. 2020;117:9490-6.

13. Cai Q, Yang M, Liu D, Chen J, Shu D, Xia J, et al. Experimental treatment with favipiravir for COVID-19: an open-label control study. Engineering (Beijing). 2020;6:1192-8.

14. Lian N, Xie H, Lin S, Huang J, Zhao J, Lin Q. Umifenovir treatment is not associated with improved outcomes in patients with coronavirus disease 2019: a retrospective study. Clin Microbiol Infect. 2020;26:917-21.

15. Ye M, Fu D, Ren Y, Wang F, Wang D, Zhang F, et al. Treatment with convalescent plasma for CoVID-19 patients in Wuhan, China. J Med Virol. 2020;92:1890-901.

16. Prompetchara E, Ketloy C, Palaga T. Immune responses in COVID-19 and potential vaccines: lessons learned from SARS and MERS epidemic. Asian Pac J Allergy Immunol. 2020;38:1-9.

17. Tahir Ul Qamar M, Alqahtani SM, Alamri MA, Chen LL. Structural basis of SARS-CoV-2 3CL ${ }^{\text {pro }}$ and antiCOVID-19 drug discovery from medicinal plants. J Pharm Anal. 2020;10:313-9.

18. Koyama S, Ishii KJ, Coban C, Akira S. Innate immune response to viral infection. Cytokine. 2008;43:336-41.

19. Flajnik MF, Du Pasquier L. Evolution of innate and adaptive immunity: can we draw a line? Trends Immunol. 2004;25:640-4.

20. Feng Y, Wang Y, Zhang S, Haneef K, Liu W. Structural and immunogenomic insights into B-cell receptor activation. J Genet Genomics. 2020;47:27-35.

21. Shaheen S, Wan Z, Haneef K, Zeng Y, Jing W, Liu W. B cell mechanosensing: a mechanistic overview. Adv Immunol. 2019;144:23-63. 
22. Shaheen S, Wan Z, Li Z, Chau A, Li X, Zhang S, et al. Substrate stiffness governs the initiation of B cell activation by the concerted signaling of PKC $\beta$ and focal adhesion kinase. Elife. 2017;6:e23060.

23. Xu C, Wan Z, Shaheen S, Wang J, Yang Z, Liu W. A PI ${ }_{4,5} \mathrm{P} 2$-derived "gasoline engine model" for the sustained B cell receptor activation. Immunol Rev. 2019;291:75-90.

24. Muniyappa R, Gubbi S. COVID-19 pandemic, coronaviruses, and diabetes mellitus. Am J Physiol Endocrinol Metab. 2020;318:E736-41.

25. De Biasi S, Lo Tartaro D, Meschiari M, Gibellini L, Bellinazzi C, Borella R, et al. Expansion of plasmablasts and loss of memory B cells in peripheral blood from COVID-19 patients with pneumonia. Eur J Immunol. 2020;50:1283-94.

26. Wan Z, Shaheen S, Chau A, Zeng Y, Liu W. Imaging: gear up for mechano-immunology. Cell Immunol. 2020;350:103926.

27. Shi Y, Wang Y, Shao C, Huang J, Gan J, Huang X, et al. COVID-19 infection: the perspectives on immune responses. Cell Death Differ. 2020;27:1451-4.

28. Gharebaghi R, Heidary F, Moradi M, Parvizi M. Metronidazole; a potential novel addition to the COVID-19 treatment regimen. Arch Acad Emerg Med. 2020;8:e40.

29. Le Bert N, Tan AT, Kunasegaran K, Tham CYL, Hafezi M, Chia A, et al. SARS-CoV-2-specific T cell immunity in cases of COVID-19 and SARS, and uninfected controls. Nature. 2020;584:457-62.

30. Jiang M, Guo Y, Luo Q, Huang Z, Zhao R, Liu S, et al. T-cell subset counts in peripheral blood can be used as discriminatory biomarkers for diagnosis and severity prediction of coronavirus disease 2019. J Infect Dis. 2020;222:198-202.

31. Diao B, Wang C, Tan Y, Chen X, Liu Y, Ning L, et al. Reduction and functional exhaustion of T cells in patients with coronavirus disease 2019 (COVID-19). Front Immunol. 2020;11:827.

32. Zhang JY, Wang XM, Xing X, Xu Z, Zhang C, Song JW, et al. Single-cell landscape of immunological responses in patients with COVID-19. Nat Immunol. 2020;21:1107-18.

33. Tan M, Liu Y, Zhou R, Deng X, Li F, Liang K, et al. Immunopathological characteristics of coronavirus disease 2019 cases in Guangzhou, China. Immunology. 2020;160:261-8.

34. Merad M, Martin JC. Pathological inflammation in patients with COVID-19: a key role for monocytes and macrophages. Nat Rev Immunol. 2020;20:355-62.

35. Jia R, Wang X, Liu P, Liang X, Ge Y, Tian H, et al. Mild cytokine elevation, moderate CD4+ ${ }^{+}$cell response and abundant antibody production in children with COVID-19. Virol Sin. 2020;35:734-43.

36. Qin C, Zhou L, Hu Z, Zhang S, Yang S, Tao Y, et al. Dysregulation of immune response in patients with coronavirus 2019 (COVID-19) in Wuhan, China. Clin Infect Dis. 2020;71:762-8.

37. Kalimuddin S, Tham CYL, Qui M, de Alwis R, Sim JXY, Lim JME, et al. Early T cell and binding antibody responses are associated with COVID-19 RNA vaccine efficacy onset. Med (N Y). 2021;2:682-8.e4.

38. Hendriks J, Xiao Y, Rossen JW, van der Sluijs KF, Sugamura K, Ishii N, et al. During viral infection of the respiratory tract, $\mathrm{CD} 27,4-1 \mathrm{BB}$, and $\mathrm{OX} 40$ collectively determine formation of $\mathrm{CD}^{+}$memory $\mathrm{T}$ cells and their capacity for secondary expansion. J Immunol. 2005;175:1665-76.

39. Zheng M, Gao Y, Wang G, Song G, Liu S, Sun D, et al. Functional exhaustion of antiviral lymphocytes in COVID-19 patients. Cell Mol Immunol. 2020;17:533-5.

40. Nassef Kadry Naguib Roufaiel M, Wells JW, Steptoe RJ. Impaired T-cell function in B-cell lymphoma: a direct consequence of events at the immunological synapse? Front Immunol. 2015;6:258.

41. Arcanjo A, Logullo J, Menezes CCB, de Souza Carvalho Giangiarulo TC, Dos Reis MC, de Castro GMM, et al. The emerging role of neutrophil extracellular traps in severe acute respiratory syndrome coronavirus 2 (COVID-19). Sci Rep. 2020;10:19630.

42. Koenig LM, Boehmer DFR, Metzger P, Schnurr M, Endres S, Rothenfusser S. Blocking inflammation on the way: rationale for CXCR2 antagonists for the treatment of COVID-19. J Exp Med. 2020;217:e20201342. 
43. Thomas WD, Hersey P. TNF-related apoptosis-inducing ligand (TRAIL) induces apoptosis in Fas ligandresistant melanoma cells and mediates CD4 T cell killing of target cells. J Immunol. 1998;161:2195-200.

44. Long QX, Liu BZ, Deng HJ, Wu GC, Deng K, Chen YK, et al. Antibody responses to SARS-CoV-2 in patients with COVID-19. Nat Med. 2020;26:845-8.

45. Lin L, Lu L, Cao W, Li T. Hypothesis for potential pathogenesis of SARS-CoV-2 infection-a review of immune changes in patients with viral pneumonia. Emerg Microbes Infect. 2020;9:727-32.

46. Noroozi R, Branicki W, Pyrc K, Łabaj PP, Pospiech E, Taheri M, et al. Altered cytokine levels and immune responses in patients with SARS-CoV-2 infection and related conditions. Cytokine. 2020;133:155143.

47. Sun B, Feng Y, Mo X, Zheng P, Wang Q Li P, et al. Kinetics of SARS-CoV-2 specific IgM and IgG responses in COVID-19 patients. Emerg Microbes Infect. 2020;9:940-8.

48. Iwasaki A, Yang Y. The potential danger of suboptimal antibody responses in COVID-19. Nat Rev Immunol. 2020;20:339-41.

49. Wang X, Guo X, Xin Q Pan Y, Hu Y, Li J, et al. Neutralizing antibody responses to severe acute respiratory syndrome coronavirus 2 in coronavirus disease 2019 inpatients and convalescent patients. Clin Infect Dis. 2020;71:2688-94.

50. Zhou G, Zhao Q. Perspectives on therapeutic neutralizing antibodies against the novel coronavirus SARSCoV-2. Int J Biol Sci. 2020;16:1718-23.

51. Tay MZ, Poh CM, Rénia L, MacAry PA, Ng LFP. The trinity of COVID-19: immunity, inflammation and intervention. Nat Rev Immunol. 2020;20:363-74.

52. Huang W, Berube J, McNamara M, Saksena S, Hartman M, Arshad T, et al. Lymphocyte subset counts in COVID-19 patients: a meta-analysis. Cytometry A. 2020;97:772-6.

53. Dustin ML. What counts in the immunological synapse? Mol Cell. 2014;54:255-62.

54. Woodruff MC, Ramonell RP, Nguyen DC, Cashman KS, Saini AS, Haddad NS, et al. Extrafollicular B cell responses correlate with neutralizing antibodies and morbidity in COVID-19. Nat Immunol. 2020;21:1506-16.

55. Ni L, Ye F, Cheng ML, Feng Y, Deng YQ Zhao H, et al. Detection of SARS-CoV-2-specific humoral and cellular immunity in COVID-19 convalescent individuals. Immunity. 2020;52:971-7.e3.

56. Azkur AK, Akdis M, Azkur D, Sokolowska M, van de Veen W, Brüggen MC, et al. Immune response to SARS-CoV-2 and mechanisms of immunopathological changes in COVID-19. Allergy. 2020;75:1564-81.

57. Schulthei $\beta$ C, Paschold L, Simnica D, Mohme M, Willscher E, von Wenserski L, et al. Next-generation sequencing of $\mathrm{T}$ and $\mathrm{B}$ cell receptor repertoires from COVID-19 patients showed signatures associated with severity of disease. Immunity. 2020;53:442-55.e4.

58. Sánchez-Cerrillo I, Landete P, Aldave B, Sánchez-Alonso S, Sánchez-Azofra A, Marcos-Jiménez A, et al. COVID-19 severity associates with pulmonary redistribution of CD1 $\mathrm{c}^{+} \mathrm{DCs}$ and inflammatory transitional and nonclassical monocytes. J Clin Invest. 2020;130:6290-300.

59. Chatterjee SK, Saha S, Munoz MNM. Molecular pathogenesis, immunopathogenesis and novel therapeutic strategy against COVID-19. Front Mol Biosci. 2020;7:196.

60. Hirano T, Murakami M. COVID-19: a new virus, but a familiar receptor and cytokine release syndrome. Immunity. 2020;52:731-3.

61. Stopsack KH, Mucci LA, Antonarakis ES, Nelson PS, Kantoff PW. TMPRSS2 and COVID-19: serendipity or opportunity for intervention? Cancer Discov. 2020;10:779-82.

62. Palau V, Riera M, Soler MJ. ADAM17 inhibition may exert a protective effect on COVID-19. Nephrol Dial Transplant. 2020;35:1071-2.

63. García LF. Immune response, inflammation, and the clinical spectrum of COVID-19. Front Immunol. 2020;11:1441. 
64. Tobin MJ, Laghi F, Jubran A. Why COVID-19 silent hypoxemia is baffling to physicians. Am J Respir Crit Care Med. 2020;202:356-60.

65. Chen Y, Shan K, Qian W. Asians do not exhibit elevated expression or unique genetic polymorphisms for ACE2, the cell-entry receptor of SARS-CoV-2. bioRxiv 2020020258 [Preprint]. 2020 [cited 2020 Feb 24]. Available from: https://www.preprints.org/manuscript/202002.0258/v2

66. Xu Y, Liu P, Gu J. Gastrointestinal and liver involvement in patients with COVID-19. Lancet Gastroenterol Hepatol. 2020;5:798-9.

67. Lee PI, Hu YL, Chen PY, Huang YC, Hsueh PR. Are children less susceptible to COVID-19? J Microbiol Immunol Infect. 2020;53:371-2.

68. Shilts J, Wright GJ. No evidence for basigin/CD147 as a direct SARS-CoV-2 spike binding receptor. bioRxiv 2020.07.25.221036 [Preprint]. 2020 [cited 2021 Jan 11]. Available from: https://www.biorxiv.org/ content/10.1101/2020.07.25.221036v1

69. Leonardi A, Rosani U, Brun P. Ocular surface expression of SARS-CoV-2 receptors. Ocul Immunol Inflamm. 2020;28:735-8.

70. Radzikowska U, Ding M, Tan G, Zhakparov D, Peng Y, Wawrzyniak P, et al. Distribution of ACE2, CD147, CD26, and other SARS-CoV-2 associated molecules in tissues and immune cells in health and in asthma, COPD, obesity, hypertension, and COVID-19 risk factors. Allergy. 2020;75:2829-45.

71. Kalita P, Padhi AK, Zhang KYJ, Tripathi T. Design of a peptide-based subunit vaccine against novel coronavirus SARS-CoV-2. Microb Pathog. 2020;145:104236.

72. Castiglione V, Chiriacò M, Emdin M, Taddei S, Vergaro G. Statin therapy in COVID-19 infection. Eur Heart J Cardiovasc Pharmacother. 2020;6:258-9.

73. Ye Q, Wang B, Mao J. The pathogenesis and treatment of the "Cytokine Storm" in COVID-19. J Infect. 2020;80:607-13.

74. Sun X, Wang T, Cai D, Hu Z, Chen J, Liao H, et al. Cytokine storm intervention in the early stages of COVID-19 pneumonia. Cytokine Growth Factor Rev. 2020;53:38-42.

75. Dashti-Khavidaki S, Khalili H. Considerations for statin therapy in patients with COVID-19. Pharmacotherapy. 2020;40:484-6.

76. Santerre M, Arjona SP, Allen CN, Shcherbik N, Sawaya BE. Why do SARS-CoV-2 NSPs rush to the ER? J Neurol. 2021;268:2013-22.

77. Angeletti S, Benvenuto D, Bianchi M, Giovanetti M, Pascarella S, Ciccozzi M. COVID-2019: the role of the nsp2 and nsp3 in its pathogenesis. J Med Virol. 2020;92:584-8.

78. Robson B. The use of knowledge management tools in viroinformatics. Example study of a highly conserved sequence motif in Nsp3 of SARS-CoV-2 as a therapeutic target. Comput Biol Med. 2020; 125:103963.

79. Li J, Guo M, Tian X, Liu C, Wang X, Yang X, et al. Virus-host interactome and proteomic survey of PMBCs from COVID-19 patients reveal potential virulence factors influencing SARS-CoV-2 pathogenesis. bio Rxiv 2020.03.31.019216 [Preprint]. 2020 [cited 2020 Jul 02]. Available from: https://www.biorxiv.org/ content/10.1101/2020.03.31.019216v1

80. Carter DC, Wright B, Jerome WG, Rose JP, Wilson E. A unique protein self-assembling nanoparticle with significant advantages in vaccine development and production. J Nanomater. 2020;2020:4297937.

81. Bharadwaj A, Wahi N, Saxena A, Chaudhary D. Proteome organization of COVID-19: illustrating targets for vaccine development. J Pure Appl Microbiol. 2020;14:831-40.

82. Florindo HF, Kleiner R, Vaskovich-Koubi D, Acúrcio RC, Carreira B, Yeini E, et al. Immune-mediated approaches against COVID-19. Nat Nanotechnol. 2020;15:630-45.

83. Larsen MD, de Graaf EL, Sonneveld ME, Plomp HR, Linty F, Visser R, et al. Afucosylated immunoglobulin $G$ responses are a hallmark of enveloped virus infections and show an exacerbated phenotype in 
COVID-19. bioRxiv 2020.05.18.099507 [Preprint]. 2020 [cited 2020 May 18]. Available from: https:// www.biorxiv.org/content/10.1101/2020.05.18.099507v1

84. Kapur R, Kustiawan I, Vestrheim A, Koeleman CA, Visser R, Einarsdottir HK, et al. A prominent lack of IgG1-Fc fucosylation of platelet alloantibodies in pregnancy. Blood. 2014;123:471-80.

85. Keam S, Megawati D, Patel SK, Tiwari R, Dhama K, Harapan H. Immunopathology and immunotherapeutic strategies in severe acute respiratory syndrome coronavirus 2 infection. Rev Med Virol. 2020;30:e2123.

86. Baum A, Fulton BO, Wloga E, Copin R, Pascal KE, Russo V, et al. Antibody cocktail to SARS-CoV-2 spike protein prevents rapid mutational escape seen with individual antibodies. Science. 2020;369:1014-8.

87. Mozdzanowska K, Feng J, Gerhard W. Virus-neutralizing activity mediated by the fab fragment of a hemagglutinin-specific antibody is sufficient for the resolution of influenza virus infection in SCID mice. J Virol. 2003;77:8322-8.

88. DiLillo DJ, Tan GS, Palese P, Ravetch JV. Broadly neutralizing hemagglutinin stalk-specific antibodies require $\mathrm{Fc} \gamma \mathrm{R}$ interactions for protection against influenza virus in vivo. Nat Med. 2014;20:143-51.

89. Jiang RD, Liu MQ, Chen Y, Shan C, Zhou YW, Shen XR, et al. Pathogenesis of SARS-CoV-2 in transgenic mice expressing human angiotensin-converting enzyme 2. Cell. 2020;182:50-8.e8.

90. Mogensen TH, Paludan SR. Molecular pathways in virus-induced cytokine production. Microbiol Mol Biol Rev. 2001;65:131-50.

91. Pinto D, Park YJ, Beltramello M, Walls AC, Tortorici MA, Bianchi S, et al. Cross-neutralization of SARSCoV-2 by a human monoclonal SARS-CoV antibody. Nature. 2020;583:290-5.

92. Daughaday CC, Brandt WE, McCown JM, Russell PK. Evidence for two mechanisms of dengue virus infection of adherent human monocytes: trypsin-sensitive virus receptors and trypsin-resistant immune complex receptors. Infect Immun. 1981;32:469-73.

93. Devaux CA, Rolain JM, Colson P, Raoult D. New insights on the antiviral effects of chloroquine against coronavirus: what to expect for COVID-19? Int J Antimicrob Agents. 2020;55:105938.

94. Ayouba A, Thaurignac G, Morquin D, Tuaillon E, Raulino R, Nkuba A, et al. Multiplex detection and dynamics of IgG antibodies to SARS-CoV2 and the highly pathogenic human coronaviruses SARS-CoV and MERS-CoV. J Clin Virol. 2020;129:104521.

95. Tsai G, Coyle JT. Glutamatergic mechanisms in schizophrenia. Annu Rev Pharmacol Toxicol. 2002; 42:165-79.

96. Chen Y, Li L. SARS-CoV-2: virus dynamics and host response. Lancet Infect Dis. 2020;20:515-6.

97. Kelvin AA, Halperin S. COVID-19 in children: the link in the transmission chain. Lancet Infect Dis. 2020;20:633-4.

98. Tian Y, Rong L, Nian W, He Y. Review article: gastrointestinal features in COVID-19 and the possibility of faecal transmission. Aliment Pharmacol Ther. 2020;51:843-51.

99. Xiao F, Sun J, Xu Y, Li F, Huang X, Li H, et al. Infectious SARS-CoV-2 in feces of patient with severe COVID-19. Emerg Infect Dis. 2020;26:1920-2.

100. Zhang B, Zhou X, Zhu C, Song Y, Feng F, Qiu Y, et al. Immune phenotyping based on the neutrophil-to-lymphocyte ratio and IgG level predicts disease severity and outcome for patients with COVID-19. Front Mol Biosci. 2020;7:157.

101. To KK, Tsang OT, Leung WS, Tam AR, Wu TC, Lung DC, et al. Temporal profiles of viral load in posterior oropharyngeal saliva samples and serum antibody responses during infection by SARS-CoV-2: an observational cohort study. Lancet Infect Dis. 2020;20:565-74.

102. Chi X, Yan R, Zhang J, Zhang G, Zhang Y, Hao M, et al. A potent neutralizing human antibody reveals the $N$-terminal domain of the Spike protein of SARS-CoV-2 as a site of vulnerability. bioRxiv 2020.05.08.083964 [Preprint]. 2020 [cited 2020 May 08]. Available from: https://www.biorxiv.org/ content/10.1101/2020.05.08.083964v1 
103. Tang XC, Agnihothram SS, Jiao Y, Stanhope J, Graham RL, Peterson EC, et al. Identification of human neutralizing antibodies against MERS-CoV and their role in virus adaptive evolution. Proc Natl Acad Sci U S A. 2014;111:E2018-26.

104. Renn A, Fu Y, Hu X, Hall MD, Simeonov A. Fruitful neutralizing antibody pipeline brings hope to defeat SARS-Cov-2. Trends Pharmacol Sci. 2020;41:815-29.

105. Zhao G, Du L, Ma C, Li Y, Li L, Poon VK, et al. A safe and convenient pseudovirus-based inhibition assay to detect neutralizing antibodies and screen for viral entry inhibitors against the novel human coronavirus MERS-CoV. Virol J. 2013;10:266.

106. Lv Z, Deng YQ, Ye Q, Cao L, Sun CY, Fan C, et al. Structural basis for neutralization of SARS-CoV-2 and SARS-CoV by a potent therapeutic antibody. Science. 2020;369:1505-9.

107. Jiang S, Hillyer C, Du L. Neutralizing antibodies against SARS-CoV-2 and other human coronaviruses. Trends Immunol. 2020;41:355-9.

108. Hansen J, Baum A, Pascal KE, Russo V, Giordano S, Wloga E, et al. Studies in humanized mice and convalescent humans yield a SARS-CoV-2 antibody cocktail. Science. 2020;369:1010-4.

109. Petrosillo N, Viceconte G, Ergonul O, Ippolito G, Petersen E. COVID-19, SARS and MERS: are they closely related? Clin Microbiol Infect. 2020;26:729-34.

110. Rehman SU, Shafique L, Ihsan A, Liu Q. Evolutionary trajectory for the emergence of novel coronavirus SARS-CoV-2. Pathogens. 2020;9:240.

111. Sardar R, Satish D, Birla S, Gupta D. Comparative analyses of SAR-CoV2 genomes from different geographical locations and other coronavirus family genomes reveals unique features potentially consequential to host-virus interaction and pathogenesis. bioRxiv 2020.03.21.001586 [Preprint]. 2020 [cited 2020 Mar 21]. Available from: https://www.biorxiv.org/content/10.1101/2020.03.21.001586v1

112. Yuan M, Wu NC, Zhu X, Lee CD, So RTY, Lv H, et al. A highly conserved cryptic epitope in the receptor binding domains of SARS-CoV-2 and SARS-CoV. Science. 2020;368:630-3.

113. Datta PK, Liu F, Fischer T, Rappaport J, Qin X. SARS-CoV-2 pandemic and research gaps: understanding SARS-CoV-2 interaction with the ACE2 receptor and implications for therapy. Theranostics. 2020; 10:7448-64.

114. Seydoux E, Homad LJ, MacCamy AJ, Parks KR, Hurlburt NK, Jennewein MF, et al. Analysis of a SARSCoV-2-infected individual reveals development of potent neutralizing antibodies with limited somatic mutation. Immunity. 2020;53:98-105.e5.

115. Hurlburt NK, Wan YH, Stuart AB, Feng J, McGuire AT, Stamatatos L, et al. Structural basis for potent neutralization of SARS-CoV-2 and role of antibody affinity maturation. bioRxiv 2020.06.12.148692 [Preprint]. 2020 [cited 2020 Oct 27]. Available from: https://www.biorxiv.org/ content/10.1101/2020.06.12.148692v1

116. Brouwer PJM, Caniels TG, van der Straten K, Snitselaar JL, Aldon Y, Bangaru S, et al. Potent neutralizing antibodies from COVID-19 patients define multiple targets of vulnerability. bioRxiv 2020.05.12.088716 [Preprint]. 2020 [cited 2020 Aug 07]. Available from: https://www.biorxiv.org/ content/10.1101/2020.05.12.088716v1

117. Mi T, Burgess K. Striking similarities between CDRs in some mAbs that neutralize COVID-19. ACS Med Chem Lett. 2020;11:1663-6. 